BMJ Open

Diabetes

Research

\& Care

\title{
Association between diabetes and edentulism and their joint effects on health status in 40 low and middle- income countries
}

\author{
Louis Jacob (1) , ${ }^{1,2,3}$ Jae II Shin, ${ }^{4}$ Hans Oh, ${ }^{5}$ Guillermo F López-Sánchez, \\ Lee Smith, ${ }^{7}$ Josep Maria Haro, ${ }^{1,2}$ Ai Koyanagi ${ }^{1,2,8}$
}

To cite: Jacob L, Shin Jl, Oh H, et al. Association between diabetes and edentulism and their joint effects on health status in 40 low and middle-income countries. BMJ Open Diab Res Care 2021;9:e002514. doi:10.1136/ bmjdrc-2021-002514

- Additional supplemental material is published online only. To view, please visit the journal online (http://dx.doi. org/10.1136/bmjdrc-2021002514).

Received 28 July 2021 Accepted 26 September 2021

\section{Check for updates}

C) Author(s) (or their employer(s)) 2021. Re-use permitted under CC BY-NC. No commercial re-use. See rights and permissions. Published by BMJ.

For numbered affiliations see end of article.

Correspondence to Dr Louis Jacob; louis.jacob.contacts@gmail. com

\section{ABSTRACT}

Introduction Previous studies on the diabetes-edentulism relationship have yielded conflicting results. Therefore, the goal of this study was to investigate the association between diabetes and edentulism, and their joint effects on health status in adults from 40 low and middle-income countries (LMICs).

Research design and methods Data from the World Health Survey were used for this cross-sectional study (2002-2004). Forty countries (18 low-income and 22 middle-income countries) were included. Edentulism and diabetes were assessed using yes-no questions based on self-report. Health status was assessed in seven different domains (self-care, pain/discomfort, cognition, interpersonal activities, sleep/ energy, affect, and perceived stress). The association between diabetes (exposure) and edentulism (outcome) was analyzed using multivariable logistic regression models, while their joint effects on health status were assessed using multivariable linear regression models.

Results There were 175814 adults aged $\geq 18$ years included in this study (mean (SD) age 38.4 (16.0) years; 49.3\% men). Overall, the prevalence of edentulism was $6.0 \%$ and diabetes was $2.9 \%$. There was a positive and significant association between diabetes and edentulism in the overall sample ( $\mathrm{OR}=1.40,95 \% \mathrm{Cl} 1.18$ to 1.66 ), in low-income countries ( $\mathrm{OR}=1.78,95 \% \mathrm{Cl} 1.21$ to 2.62$)$ and in middleincome countries $(\mathrm{OR}=1.24,95 \% \mathrm{Cl} 1.04$ to 1.47$)$. In addition, people with comorbid diabetes and edentulism had worse health status in the domains of cognition, sleep/energy, and perceived stress, compared with those with diabetes only. Conclusions Diabetes was positively associated with edentulism in this sample of more than 175000 individuals living in LMICs. Providing oral care to individuals with diabetes may potentially lead to a reduction in their risk of edentulism.

\section{INTRODUCTION}

Edentulism is a chronic condition defined as the permanent loss of all natural teeth. ${ }^{1}$ The prevalence of edentulism is high in the world, and reaches $12 \%$ among older adults living in low and middle-income countries (LMICs). ${ }^{2}$ Edentulism is associated with poor self-rated health, ${ }^{3}$ psychiatric diseases ${ }^{4}$ and low quality of life, ${ }^{5}$ and these associations may be more pronounced in LMICs, where access to

\section{Significance of this study}

What is already known about this subject?

- Studies that have investigated the association between diabetes and edentulism have yielded conflicting findings.

What are the new findings?

- There was a positive and significant association between diabetes and edentulism in a large sample of adults from low and middle-income countries. Among those with diabetes, having comorbid edentulism was associated with significant declines in health status in the domains of cognition, sleep/ energy and perceived stress.

How might these results change the focus of research or clinical practice?

- These results highlight the importance of measures (eg, promotion of regular tooth brushing, use of fluoride toothpaste, decreased tobacco consumption) aiming at the prevention of edentulism among people with diabetes.

healthcare services is limited. ${ }^{6}$ In this context, research aiming at better understanding the epidemiology and risk factors of edentulism in these countries is urgently needed.

In the last decades, numerous studies have focused on the association between diabetes and edentulism, and these studies have reported conflicting findings. ${ }^{2}{ }^{7-11}$ For example, a cross-sectional study including 2508 participants from the USA showed that diabetes was significantly associated with edentulism after adjusting for several sociodemographic and behavioral factors. ${ }^{8}$ In contrast, another study of 35334 older adults from six LMICs found no significant relationship between diabetes and edentulism. ${ }^{2}$ Diabetes may increase risk for edentulism via the direct oral manifestations of diabetes (eg, xerostomia, dental caries and gingival 
inflammation $)^{12}$ and also by several mediating factors (eg, depression, ${ }^{13} 14$ cognitive impairment ${ }^{1516}$ and pain $^{1718}$ ). However, it is unclear whether diabetes is associated with edentulism. Given the contradicting results on this association from previous studies, it is possible that the association between diabetes and edentulism is context specific, and more multicountry data are thus needed to identify potential between-country differences on the association between diabetes and edentulism. Finally, to the best of the authors' knowledge, no study has yet compared the health of people with both diabetes and edentulism and the health of those with diabetes only. Diabetes and edentulism may have joint deleterious effects on several health domains such as pain, sleep and perceived stress, and analyzing these effects is necessary to understand the health outcome of this comorbidity.

Therefore, the primary aim of this cross-sectional study was to investigate the association between diabetes and edentulism in a sample of more than 175800 adults living in 40 LMICs. The secondary goal was to analyze the dual effects of diabetes and edentulism on health status compared with diabetes alone. It was hypothesized that diabetes would be positively and significantly associated with edentulism, and that individuals affected by both diabetes and edentulism would have a worse health status than their counterparts with diabetes only. Given that diabetes is a highly prevalent disorder in LMICs, while its prevalence is increasing drastically due to changes in lifestyles in this setting, ${ }^{19}$ assessing the diabetes-edentulism relationship in these countries is a public health priority.

\section{METHODS}

The survey

The World Health Survey (WHS) was a cross-sectional survey conducted in 70 countries between 2002 and 2004. Singlestage and multistage random cluster samplings were undertaken in 10 and 60 countries, respectively. More details on the WHS are accessible at https://appswhoint/healthinfo/ systems/surveydata/indexphp/catalog/whs/about. To summarize, the eligible sample included all people aged $\geq 18$ years who had a valid home address at the time of the survey. One individual per household was selected using Kish tables, and the probability to be selected was equal between all members of the same household. To ensure comparability between countries, questionnaires were translated using standard procedures. Data were collected by trained staff during face-to-face and telephone interviews. The overall response rate in the WHS was $98.5 \%$. Based on the United Nations Statistical Division's population distribution, sampling weights were created to adjust for non-response. Informed consent was obtained from each participant.

Data were publicly available for 69 countries. Among these 69 countries, there was a lack of sampling information for 10 countries, and these countries were therefore excluded. Furthermore, given that this study focused on LMICs, 10 high-income countries were further excluded from the analysis. Eight LMICs with more than $25 \%$ of missing data on edentulism or diabetes were also excluded. Finally, there were no data on diabetes in Turkey, and this country was also omitted from the study. Thus, the final sample consisted of 40 LMICs including 175814 individuals. Based on the classification of the World Bank at the time of the survey in 2003, there were 18 low-income ( $\mathrm{n}=93423)$ and 22 middle-income countries $(n=82391)$. A list of all countries included in this study with their respective sample size is available in online supplemental table 1. Data were nationally representative for all countries except China, Comoros, India, Ivory Coast, and Russia.

\section{Edentulism and diabetes}

Edentulism was assessed by the question 'Have you lost all your natural teeth?' Participants answering 'yes' were considered to have edentulism. In addition, those who answered 'yes' to the question 'Have you ever been diagnosed with diabetes (high blood sugar)?' were considered to have diabetes.

\section{Health status}

Seven domains were used to assess health status: (a) self-care; (b) pain/discomfort; (c) cognition; (d) interpersonal activities; (e) sleep/energy; (f) affect; and (g) perceived stress. These seven domains, which correspond to common health outcome measures (eg, the Short Form 12, ${ }^{20}$ the Health Utilities Index Mark $3^{21}$ and the EuroQol-5D ${ }^{22}$ ), have been used as proxies of health status in several WHS studies. ${ }^{23} 24$ Each of the seven domains included two questions assessing past-month health function. Each item was scored on a fivepoint scale, and this score ranged from 'none' to 'extreme/ cannot do'. One exception was perceived stress, as perceived stress was assessed using two questions from the Perceived Stress Scale with a five-point scale ranging from 'never' to 'very often'. All questions are displayed in online supplemental table 2. A factor analysis with polychoric correlations was further used for each of the seven health status domains to obtain a factor score ranging from 0 to 100 , with higher values corresponding to decreased health function. ${ }^{24} 25$ There were no data on affect in Morocco, and there were no data on perceived stress in Brazil, Hungary and Zimbabwe.

\section{Control variables}

Previous literature was used to select control variables, ${ }^{26}$ and these included age, sex, wealth, highest level of education achieved (ie, no formal education, primary, secondary, and tertiary), current smoking, and heavy alcohol consumption. Country-wise wealth quintiles were obtained using a principal component analysis including between 15 and 20 assets. Finally, participants were considered to be lifetime alcohol abstainers if they answered 'no' to the question 'Have you ever consumed a drink that contains alcohol (such as beer, wine, etc)?' Those replying 'yes' to this question were further asked to quantify the amount of standard drinks of any alcohol beverage consumed on each day of the past week. Women and men reporting a consumption of at least four and five drinks in at least 2 days during the last week were considered to be heavy drinkers. ${ }^{27} 28$ 


\section{Statistical analysis}

Statistical analyses were performed with Stata V.14.1 (StataCorp, College Station, Texas). Sample characteristics were described using percentages except for age and health status (mean and SD). Multivariable logistic regression analysis was conducted to assess the association between diabetes (exposure) and edentulism (outcome). Analyses were conducted for the overall sample and also for country-income stratified samples (ie, low-income countries and middle-income countries). Next, based on the presence or absence of diabetes and edentulism, a four-category variable was created (ie, no diabetes and no edentulism $(n=148393)$, edentulism without diabetes $(n=9746)$, diabetes without edentulism $(n=3701)$, and diabetes with edentulism $(n=919))$ to assess whether diabetes with edentulism is associated with a larger decrement in health status as compared with diabetes alone. Multivariable linear regression analysis was conducted with this four-category variable as the exposure and the health status variables as the outcomes. Furthermore, in order to assess whether the difference between diabetes alone and comorbid diabetes/edentulism is statistically significant, the same analysis was conducted but changing the reference category to diabetes alone. All regression analyses were adjusted for age, sex, wealth, education, smoking, heavy drinking, and country. Adjustment for country was done by including dummy variables in the models as in previous WHS publications. ${ }^{23} 29$ Complete case analysis was done. The sample weighting and the complex study design were taken into account in all analyses. Results from the logistic and linear regressions are presented as ORs and b-coefficients, respectively, with $95 \%$ CIs. The level of statistical significance was set at $\mathrm{p}<0.05$.

\section{RESULTS}

The analytical sample consisted of 175814 individuals with a mean (SD) age of 38.4 (16.0) years and $49.3 \%$ were men (table 1). Overall, the prevalence of edentulism and diabetes was $6.0 \%$ and $2.9 \%$, respectively. The prevalence of edentulism was higher among those with diabetes than in those without diabetes overall $(19.1 \%$ vs $5.5 \%)$, in low-income countries $(11.0 \%$ vs $3.1 \%$ ) and in middle-income countries $(25.0 \%$ vs $9.5 \%)$ (figure 1$)$. The results of the multivariable logistic regression using the overall sample showed that diabetes was associated with 1.40 (95\% CI 1.18 to 1.66) times higher odds for edentulism (table 2). The association was stronger in low-income countries than in middle-income countries $(\mathrm{OR}=1.78,95 \%$ CI 1.21 to 2.62 vs $1.24,95 \%$ CI 1.04 to 1.47$)$. Compared with those without diabetes and edentulism, diabetes alone and comorbid diabetes/edentulism were associated with significantly worse health status in all domains (table 3). As for edentulism alone, this was significantly associated with worse health status in the domains of self-care, pain/discomfort, cognition, and sleep/energy. Among those with diabetes, having comorbid edentulism was associated with significant declines in health status in the domains of cognition, sleep/energy and perceived stress (table 4).

Table 1 Sample characteristics

\begin{tabular}{llllc}
\hline Characteristic & & Overall & Low-income countries & Middle-income countries \\
\hline Edentulism & Yes & 6.0 & 3.4 & 10.3 \\
Diabetes & Yes & 2.9 & 2.0 & 4.5 \\
\hline Age (years) & Mean (SD) & $38.4(16.0)$ & $36.8(15.3)$ & $41.1(16.8)$ \\
\hline Sex & Male & 49.3 & 50.6 & 47.2 \\
\hline Education & No formal & 28.1 & 40.2 & 8.0 \\
& Primary & 32.2 & 33.1 & 30.5 \\
& Secondary & 29.9 & 20.6 & 45.3 \\
\hline Smoking & Tertiary & 9.9 & 6.1 & 16.2 \\
\hline Heavy drinking & Yes & 26.7 & 26.9 & 26.5 \\
\hline Self-care & Yes & 4.9 & 2.2 & 9.2 \\
\hline Pain/discomfort & Mean (SD) & $11.0(23.4)$ & $12.1(24.2)$ & $9.8(22.4)$ \\
\hline Cognition & Mean (SD) & $26.3(27.0)$ & $26.0(27.2)$ & $26.6(26.7)$ \\
\hline Interpersonal activities & Mean (SD) & $20.3(26.0)$ & $20.1(25.7)$ & $20.6(26.2)$ \\
\hline Sleep/energy & Mean (SD) & $13.9(24.0)$ & $13.5(24.0)$ & $14.4(24.1)$ \\
\hline Affect & Mean (SD) & $22.1(26.1)$ & $20.6(26.0)$ & $23.7(26.2)$ \\
\hline Perceived stress & Mean (SD) & $25.4(27.7)$ & $24.1(28.0)$ & $27.0(27.3)$ \\
\hline Mean (SD) & $34.5(27.2)$ & $36.8(28.5)$ & $31.9(25.4)$ \\
\hline
\end{tabular}

Data are \% unless otherwise stated.

Health status (ie, self-care, pain/discomfort, cognition, interpersonal activities, sleep/energy, affect, and perceived stress) ranged from 0 to 100 with higher scores corresponding to worse health status. 


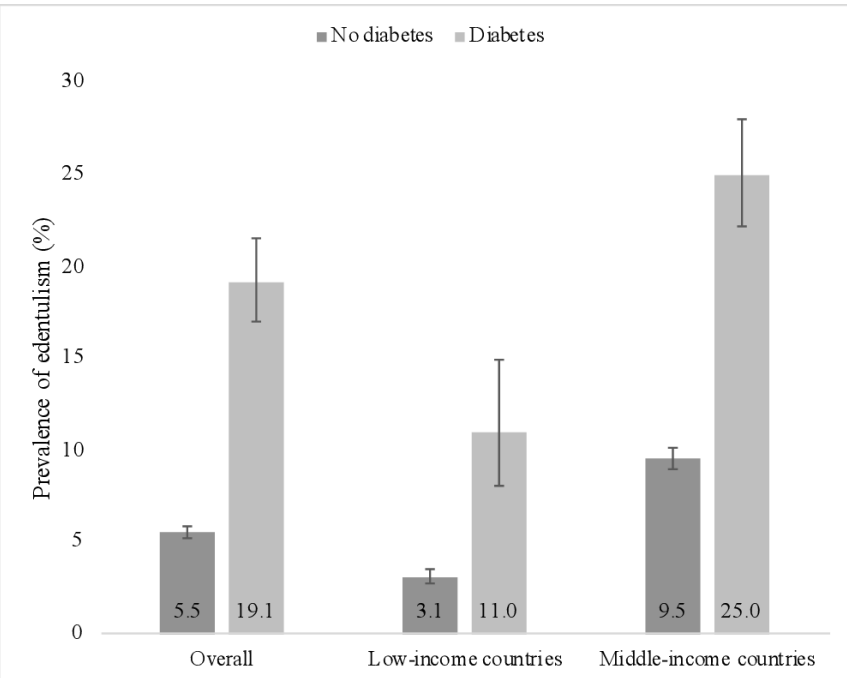

Figure 1 Prevalence of edentulism by presence or absence of diabetes. Bars denote $95 \% \mathrm{Cl}$.

\section{DISCUSSION}

\section{Main findings}

This study, including around 175800 people from 40 LMICs, showed that the prevalence of diabetes and edentulism was $2.9 \%$ and $6.0 \%$, respectively. In addition, there was a positive and significant association between diabetes and edentulism in the overall sample, low-income countries, and middle-income countries. Finally, participants with both diabetes and edentulism had worse health status in the domains of cognition, sleep/energy and perceived stress than those with diabetes only. To the best of our knowledge, this is one of the largest and one of the first multicountry studies conducted in LMICs investigating the diabetes-edentulism relationship.

\section{Interpretation of the findings}

One major finding of this study is that diabetes was significantly associated with edentulism. Interestingly, the association between diabetes and edentulism has been at the center of an important scientific debate in the past years. ${ }^{27-11}$ For example, a cross-sectional study of 15965 Hispanic/Latino adults from the USA revealed a positive and significant association between uncontrolled diabetes (ie, diabetes with glycosylated hemoglobin (HbA1c) higher or equal to 7\%), and having at least nine missing teeth or edentulism. ${ }^{7}$ It was observed in another study, including 17167 community-dwelling middle-aged and older adults from China, that diabetes was not significantly associated with edentulism after adjusting for a wide range of variables (eg, gender, place of residence and income level) ${ }^{10}{ }^{10}$ Finally, a study of Indonesian crosssectional data $(\mathrm{n}=7994$ older adults) found a negative relationship between diabetes and edentulism in men. ${ }^{9}$

\begin{tabular}{|c|c|c|c|c|c|c|c|}
\hline Characteristic & & \multicolumn{2}{|l|}{ Overall } & \multicolumn{2}{|c|}{ Low-income countries } & \multicolumn{2}{|c|}{ Middle-income countries } \\
\hline \multirow[t]{2}{*}{ Diabetes } & No & Reference & & & & & \\
\hline & Yes & $1.40^{\star \star \star}$ & 1.18 to 1.66 & $1.78^{\star \star}$ & 1.21 to 2.62 & $1.24^{\star}$ & 1.04 to 1.47 \\
\hline Sex & Male & $0.71^{\star \star *}$ & 0.64 to 0.78 & $0.81^{*}$ & 0.68 to 0.96 & $0.63^{\star \star \star}$ & 0.56 to 0.72 \\
\hline \multirow[t]{3}{*}{ Wealth } & Poorest & Reference & & & & & \\
\hline & Poorer & 1.10 & 0.97 to 1.25 & 1.28 & 0.99 to 1.66 & 1.04 & 0.90 to 1.20 \\
\hline & Middle & 0.95 & 0.82 to 1.11 & 1.04 & 0.76 to 1.42 & 0.95 & 0.80 to 1.13 \\
\hline \multirow{3}{*}{ Education } & Primary & 1.01 & 0.88 to 1.16 & 0.99 & 0.80 to 1.23 & 0.85 & 0.71 to 1.01 \\
\hline & Secondary & $0.75^{\star \star}$ & 0.63 to 0.89 & 1.00 & 0.77 to 1.31 & $0.56^{\star \star \star}$ & 0.45 to 0.70 \\
\hline & Tertiary & $0.50^{\star \star \star}$ & 0.40 to 0.64 & 0.71 & 0.43 to 1.15 & $0.38^{\star \star \star}$ & 0.29 to 0.50 \\
\hline \multirow[t]{2}{*}{ Smoking } & No & Reference & & & & & \\
\hline & Yes & $1.20^{\star \star}$ & 1.07 to 1.34 & $1.22^{*}$ & 1.00 to 1.49 & $1.21^{\star \star}$ & 1.06 to 1.38 \\
\hline \multirow[t]{2}{*}{ Heavy drinking } & No & Reference & & & & & \\
\hline & Yes & 0.85 & 0.66 to 1.10 & 0.82 & 0.55 to 1.21 & 0.90 & 0.67 to 1.21 \\
\hline
\end{tabular}

Models are mutually adjusted for all variables displayed in the table and country.

${ }^{*} \mathrm{P}<0.05 ;{ }^{* *} \mathrm{p}<0.01 ;{ }^{* * *} \mathrm{p}<0.001$. 
Table 3 Association between edentulism/diabetes groups and health status (outcome) estimated by multivariable linear regression

\begin{tabular}{|c|c|c|c|}
\hline \multirow[b]{3}{*}{ Health status (outcome) } & Edentulism (+) & Edentulism (-) & Edentulism (+) \\
\hline & Diabetes (-) & Diabetes (+) & Diabetes (+) \\
\hline & B-coefficient $(95 \% \mathrm{Cl})$ & B-coefficient $(95 \% \mathrm{Cl})$ & B-coefficient $(95 \% \mathrm{Cl})$ \\
\hline Self-care & $2.90^{\star \star \star}(1.69$ to 4.10$)$ & $5.43^{\star \star \star}(3.36$ to 7.50$)$ & $8.93^{\star \star \star}(4.85$ to 13.01$)$ \\
\hline Pain/discomfort & $1.98^{\star \star}(0.72$ to 3.24$)$ & $9.28^{\star \star \star}(7.55$ to 11.01$)$ & $8.04^{\star \star \star}(4.46$ to 11.61$)$ \\
\hline Cognition & $3.48^{\star \star \star}(2.18$ to 4.77$)$ & $4.38^{\star \star \star}(2.52$ to 6.23$)$ & $12.01^{* \star *}(8.52$ to 15.50$)$ \\
\hline Interpersonal activities & $0.84(-0.42$ to 2.10$)$ & $4.42^{\star \star \star}(2.55$ to 6.28$)$ & $5.67^{\star \star}(1.72$ to 9.63$)$ \\
\hline Sleep/energy & $1.75^{\star \star}(0.50$ to 3.00$)$ & $7.72^{\star \star \star}(5.61$ to 9.82$)$ & $11.76^{\star \star \star}(8.40$ to 15.12$)$ \\
\hline Affect $†$ & $0.06(-1.29$ to 1.40$)$ & $8.46^{\star \star *}(6.32$ to 10.60$)$ & $7.05^{\star \star \star}$ (3.39 to 10.71$)$ \\
\hline Perceived stress $\ddagger$ & 1.23 (-0.13 to 2.60$)$ & $3.11^{\star \star}$ (1.25 to 4.97$)$ & $8.75^{\star \star \star}(3.91$ to 13.58$)$ \\
\hline
\end{tabular}

Symbol '+' denotes presence; symbol '-' denotes absence. Reference category is edentulism (-), diabetes (-).

Health status was the outcome and scores ranged from 0 to 100 with higher scores corresponding to worse health status.

Models are adjusted for age, sex, wealth, education, smoking, heavy drinking, and country.

${ }^{* *} \mathrm{P}<0.01 ;{ }^{* * *} \mathrm{p}<0.001$.

†Morocco is not included due to lack of data.

‡Brazil, Hungary, and Zimbabwe are not included due to lack of data.

Several factors may explain the discrepancy between the findings of these various studies. These pieces of research were conducted in different countries, and as there are substantial differences in the management of diabetes and oral health between countries, ${ }^{30} 31$ one may hypothesize that the diabetes-edentulism relationship is context specific. Moreover, the definition of diabetes and edentulism varied between these studies, which could partly explain the differential results. For example, diabetes was self-reported ${ }^{2}$ or defined using biological parameters (eg, HbA1c and fasting glucose), ${ }^{7}$ while edentulism was assessed based on self-report ${ }^{10}$ or oral examination. ${ }^{8}$ Lastly, it should also be noted that regression models were not adjusted for the same set of variables, potentially resulting in different effect sizes.

Table 4 Association between edentulism and health status (outcome) among those with diabetes estimated by multivariable linear regression

\begin{tabular}{lcc}
\hline Health status & B-coefficient & $\mathbf{9 5 \%} \mathbf{C l}$ \\
\hline Self-care & 3.50 & -1.07 to 8.07 \\
Pain/discomfort & -1.24 & -5.17 to 2.68 \\
\hline Cognition & $7.63^{\star * *}$ & 3.62 to 11.65 \\
\hline Interpersonal activities & 1.26 & -3.06 to 5.58 \\
Sleep/energy & $4.04^{*}$ & 0.10 to 7.98 \\
Affect $†$ & -1.41 & -5.63 to 2.82 \\
Perceived stress $\ddagger$ & $5.64^{*}$ & 0.59 to 10.69 \\
\hline
\end{tabular}

Health status was the outcome and scores ranged from 0 to 100 with higher scores corresponding to worse health status. Models are adjusted for age, sex, wealth, education, smoking, heavy drinking, and country.

${ }^{*} \mathrm{P}<0.05 ;{ }^{\star * \star} \mathrm{p}<0.001$.

†Morocco is not included due to lack of data.

$\ddagger$ Brazil, Hungary, and Zimbabwe are not included due to lack of data.
The present study, including a sample of 40 countries, adds to the literature by showing that, overall, there is an association between diabetes and edentulism in LMICs. Although the design of the study was cross-sectional, several hypotheses may be elaborated to explain the diabetes-edentulism relationship. First, diabetes is frequently associated with oral symptoms, ${ }^{12}$ and these manifestations may favor the occurrence of edentulism in people with diabetes. One systematic review of 15 studies revealed that the prevalence of xerostomia was higher in people with diabetes $(12.5 \%-53.5 \%)$ than in their counterparts without diabetes $(0 \%-30 \%) .^{32}$ Another study, including 65295 participants from Spain, further found a significant association between diabetes and periodontal disease. ${ }^{33}$ In turn, both xerostomia ${ }^{34}$ and periodontal disease $^{35}$ are risk factors for the occurrence of tooth loss and edentulism. Second, the effects of diabetes on edentulism may be mediated by several factors. Indeed, diabetes is a well-known risk factor for depression, ${ }^{14}$ and depression may lead to edentulism via poor oral health, changes in the salivary immunity and changes in the oral flora. ${ }^{13}$ In addition, there is some research suggesting that cognitive impairment is relatively frequent in people with diabetes ${ }^{16}$ and cognitive impairment is associated with poor oral care and ultimately with edentulism. ${ }^{15}$ Finally, neuropathic pain is a frequent complication of diabetes, ${ }^{17}$ and pain has been identified as a predictor of edentulism. $^{18}$

Another interesting result of the present study is that participants with both diabetes and edentulism had a lower health status than their counterparts with diabetes only. This critical finding underlines the cumulative deleterious effects of these two chronic conditions on health. A substantial body of research suggests that the presence of periodontal diseases is a risk factor for insufficient glycemic control in patients affected by diabetes. ${ }^{1136-39} \mathrm{~A}$ 
longitudinal study, including 105 participants with noninsulin-dependent diabetes mellitus from the USA, found a significant association between severe periodontitis at baseline and poor glycemic control at follow-up. ${ }^{38}$ Meanwhile, periodontal diseases favor the occurrence of tooth loss and ultimately edentulism. ${ }^{40}$ Furthermore, a systematic review and meta-analysis of 25 studies $(\mathrm{n}=976$ individuals) indicated that periodontal treatment might be associated with a significant decrease in HbAlc levels. ${ }^{36}$ Given that poor oral health leads to insufficient glycemic control, patients with diabetes with poor oral health may be at a particular risk for diabetes complications, and indirectly for poor overall health. It should also be noted that edentulism may have deleterious effects on specific aspects of health (eg, cognition, sleep and perceived stress) that are independent of diabetes, highlighting the fact that the higher risk of poor health status in adults with both diabetes and edentulism compared with their counterparts with diabetes only is likely to be a multifactorial phenomenon.

\section{Clinical implications and directions for future research}

Based on the findings of this study, measures should be taken to reduce the higher risk of edentulism in adults with diabetes, and these measures may include the promotion of regular tooth brushing, ${ }^{41}$ use of fluoride toothpaste, ${ }^{42}$ and decreased tobacco consumption. ${ }^{43}$ The prevention of oral disorders is of utmost importance in LMICs where access to dental care is limited for financial and geographical reasons. ${ }^{44}$ In terms of future research, more data of longitudinal nature are needed to better characterize the causality of the association between diabetes and edentulism, and to better identify factors playing a potential mediating role in this relationship. Besides, future studies should also investigate the reverse association (ie, edentulism leading to insufficient glycemic control and diabetes) and the underlying mechanisms (eg, poor nutrition ${ }^{45}$ ).

\section{Strengths and limitations}

Major strengths of this study are the large sample size and the use of multicountry data. However, this study also has several limitations, and the findings should also be interpreted with some caution. First, the definition of diabetes and edentulism relied on yes-no questions, and this may have biased the results of this study. It is possible that particularly in resource-limited settings, there is an underdiagnosis of diabetes, while those with a diabetes diagnosis may be those with severe diabetes. Second, there were no data on the severity of diabetes, and it was therefore not possible to analyze the impact of the severity of diabetes on the risk of edentulism. Third, some confounding factors (eg, frequency of tooth brushing ${ }^{46}$ ) were not included in the regression analysis, and this may have biased the study findings. Fourth, this study only included people with a valid home address, and as poor oral health may be higher in homeless or institutionalized individuals, ${ }^{48}$ the prevalence of edentulism may have been underestimated in this study.
Fifth, the data were collected in 2002-2004, and thus it is possible that the results do not reflect the current situation as the profiles of diabetes and edentulism could have changed. Sixth, this was a cross-sectional study, and it was not possible to determine the causality or the temporality of the association between diabetes and edentulism. Thus, these results should be considered preliminary, and future prospective studies are warranted on this topic.

\section{CONCLUSIONS}

This study conducted in LMICs found a positive and significant relationship between diabetes and edentulism. In addition, individuals with both diabetes and edentulism had a worse health status than those with diabetes only. In this context, there is an urgent need to promote oral health in people with diabetes. Finally, more research is warranted to corroborate or invalidate the present findings, while future longitudinal studies should identify the mechanisms involved in the association between diabetes and edentulism.

\section{Author affiliations}

${ }^{1}$ Research and Development Unit, Parc Sanitari Sant Joan de Deu, Sant Boi de Llobregat, Spain

${ }^{2}$ Centro de Investigación Biomédica en Red de Salud Mental (CIBERSAM), Madrid, Spain

${ }^{3}$ Faculty of Medicine, University of Versailles Saint-Quentin-en-Yvelines, Montignyle-Bretonneux, France

${ }^{4}$ Department of Pediatrics, Yonsei University College of Medicine, Seoul, South Korea

${ }^{5}$ Suzanne Dworak Peck School of Social Work, University of Southern California, Los Angeles, California, USA

${ }^{6}$ Vision and Eye Research Institute, School of Medicine, Faculty of Health, Education, Medicine and Social Care, Anglia Ruskin University-Cambridge Campus, Cambridge, UK

${ }^{7}$ The Cambridge Centre for Sport and Exercise Sciences, Anglia Ruskin UniversityCambridge Campus, Cambridge, UK

${ }^{8}$ ICREA, Pg. Lluis Companys 23, Barcelona, Spain

Contributors LJ contributed to the design of the study, managed the literature searches, wrote the first draft of the manuscript, and corrected the manuscript JIIS, HO, GFL-S, LS, and JMH contributed to the design of the study and corrected the manuscript. AK contributed to the design of the study, performed the statistical analyses, and corrected the manuscript. All authors contributed to and have approved the final manuscript.

Funding The authors have not declared a specific grant for this research from any funding agency in the public, commercial or not-for-profit sectors.

Competing interests None declared.

Patient consent for publication Not applicable.

Ethics approval Ethical approval was provided by all study sites.

Provenance and peer review Not commissioned; externally peer reviewed.

Data availability statement Data are available in a public, open access repository. Data are available at: https://apps.who.int/healthinfo/systems/ surveydata/index.php/catalog/whs/about

Supplemental material This content has been supplied by the author(s). It has not been vetted by BMJ Publishing Group Limited (BMJ) and may not have been peer-reviewed. Any opinions or recommendations discussed are solely those of the author(s) and are not endorsed by BMJ. BMJ disclaims all liability and responsibility arising from any reliance placed on the content. Where the content includes any translated material, BMJ does not warrant the accuracy and reliability of the translations (including but not limited to local regulations, clinical guidelines, terminology, drug names and drug dosages), and is not responsible for any error and/or omissions arising from translation and adaptation or otherwise. 
Open access This is an open access article distributed in accordance with the Creative Commons Attribution Non Commercial (CC BY-NC 4.0) license, which permits others to distribute, remix, adapt, build upon this work non-commercially, and license their derivative works on different terms, provided the original work is properly cited, appropriate credit is given, any changes made indicated, and the use is non-commercial. See: http://creativecommons.org/licenses/by-nc/4.0/.

ORCID iD

Louis Jacob http://orcid.org/0000-0003-1071-1239

\section{REFERENCES}

1 Nagaraj E, Mankani N, Madalli P, et al. Socioeconomic factors and complete edentulism in North Karnataka population. J Indian Prosthodont Soc 2014;14:24-8.

2 Peltzer K, Hewlett S, Yawson AE, et al. Prevalence of loss of all teeth (edentulism) and associated factors in older adults in China, Ghana, India, Mexico, Russia and South Africa. Int J Environ Res Public Health 2014;11:11308-24.

3 Borda MG, Castellanos-Perilla N, Patiño JA, et al. Edentulism and its relationship with self-rated health: secondary analysis of the SABE Ecuador 2009 study. Acta Odontol Latinoam 2017;30:83-9.

4 Tyrovolas S, Koyanagi A, Panagiotakos DB, et al. Population prevalence of edentulism and its association with depression and self-rated health. Sci Rep 2016;6:37083.

5 Hewlett SA, Yawson AE, Calys-Tagoe BNL, et al. Edentulism and quality of life among older Ghanaian adults. BMC Oral Health 2015; $15: 48$.

6 Druetz T. Integrated primary health care in low- and middle-income countries: a double challenge. BMC Med Ethics 2018;19:48.

7 Greenblatt AP, Salazar CR, Northridge ME, et al. Association of diabetes with tooth loss in Hispanic/Latino adults: findings from the Hispanic community health Study/Study of Latinos. BMJ Open Diabetes Res Care 2016;4:e000211.

8 Patel MH, Kumar JV, Moss ME. Diabetes and tooth loss: an analysis of data from the National health and nutrition examination survey, 2003-2004. J Am Dent Assoc 2013;144:478-85.

9 Pengpid S, Peltzer K. The prevalence of edentulism and their related factors in Indonesia, 2014/15. BMC Oral Health 2018;18:118.

10 Ren C, McGrath C, Yang Y. Edentulism and associated factors among community-dwelling middle-aged and elderly adults in China. Gerodontology 2017;34:195-207.

11 Taboza ZA, Costa KL, Silveira VR, et al. Periodontitis, edentulism and glycemic control in patients with type 2 diabetes: a crosssectional study. BMJ Open Diabetes Res Care 2018;6:e000453.

12 Rohani B. Oral manifestations in patients with diabetes mellitus. World J Diabetes 2019;10:485-9.

13 Cademartori MG, Gastal MT, Nascimento GG, et al. Is depression associated with oral health outcomes in adults and elders? A systematic review and meta-analysis. Clin Oral Investig 2018;22:2685-702.

14 Chireh B, Li M, D'Arcy C. Diabetes increases the risk of depression: a systematic review, meta-analysis and estimates of population attributable fractions based on prospective studies. Prev Med Rep 2019;14:100822.

15 Naorungroj S, Slade GD, Beck JD, et al. Cognitive decline and oral health in middle-aged adults in the ARIC study. J Dent Res 2013:92:795-801.

16 Wennberg AMV, Hagen CE, Gottesman RF, et al. Longitudinal association between diabetes and cognitive decline: the National health and aging trends study. Arch Gerontol Geriatr 2017;72:39-44

17 Rosenberger DC, Blechschmidt V, Timmerman H, et al. Challenges of neuropathic pain: focus on diabetic neuropathy. J Neural Transm 2020;127:589-624.

18 Weintraub JA, Orleans B, Fontana M, et al. Factors associated with becoming edentulous in the US health and retirement study. J Am Geriatr Soc 2019;67:2318-24.

19 Shen J, Kondal D, Rubinstein A, et al. A multiethnic study of prediabetes and diabetes in LMIC. Glob Heart 2016;11:61-70.

20 Ware J, Kosinski M, Keller SD. A 12-Item short-form health survey: construction of scales and preliminary tests of reliability and validity. Med Care 1996;34:220-33.

21 Feeny D, Furlong W, Boyle M, et al. Multi-attribute health status classification systems. health Utilities index. Pharmacoeconomics 1995;7:490-502

22 Kind P. The EuroQol instrument: an index of health-related quality of life. Quality of Life and Pharmacoeconomics in Clinical Trials, 1996: 191-201.
23 Koyanagi A, Oh H, Stickley A, et al. Risk and functional significance of psychotic experiences among individuals with depression in 44 low- and middle-income countries. Psychol Med 2016;46:2655-65.

24 Stubbs B, Koyanagi A, Schuch F, et al. Physical activity levels and psychosis: a mediation analysis of factors influencing physical activity target achievement among 204186 people across 46 lowand middle-income countries. Schizophr Bull 2017;43:536-45.

25 Vancampfort D, Koyanagi A, Ward PB, et al. Perceived stress and its relationship with chronic medical conditions and multimorbidity among 229,293 community-dwelling adults in 44 low- and middleincome countries. Am J Epidemiol 2017;186:979-89.

26 Rawal I, Ghosh S, Hameed SS, et al. Association between poor oral health and diabetes among Indian adult population: potential for integration with NCDS. BMC Oral Health 2019;19:191.

27 Vancampfort D, Stubbs B, Hallgren M, et al. Physical activity correlates in heavy episodic drinkers: data from 46 low- and middleincome countries. Ment Health Phys Act 2017;13:163-70.

28 World Health Organization. International guide for monitoring alcohol consumption and related harm. Geneva, 2000. Available: https:// apps.who.int/iris/handle/10665/66529

29 Stubbs B, Koyanagi A, Veronese N, et al. Physical multimorbidity and psychosis: comprehensive cross sectional analysis including 242,952 people across 48 low- and middle-income countries. BMC Med 2016;14:189.

30 Kandelman D, Arpin S, Baez RJ, et al. Oral health care systems in developing and developed countries. Periodontol 2000 2012;60:98-109.

31 Mohan V, Khunti K, Chan SP, et al. Management of type 2 diabetes in developing countries: balancing optimal glycaemic control and outcomes with affordability and accessibility to treatment. Diabetes Ther 2020;11:15-35.

32 López-Pintor RM, Casañas E, González-Serrano J, et al. Xerostomia, hyposalivation, and salivary flow in diabetes patients. J Diabetes Res 2016;2016:1-15

33 de Miguel-Infante A, Martinez-Huedo MA, Mora-Zamorano E. Periodontal disease in adults with diabetes, prevalence and risk factors. Results of an observational study. Int J Clin Pract 2018:e13294.

34 Guggenheimer J, Moore PA. Xerostomia: etiology, recognition and treatment. J Am Dent Assoc 2003;134:61-9.

35 Martinez-Canut P. Predictors of tooth loss due to periodontal disease in patients following long-term periodontal maintenance. $J$ Clin Periodontol 2015;42:1115-25.

36 Darré L, Vergnes J-N, Gourdy P, et al. Efficacy of periodontal treatment on glycaemic control in diabetic patients: a meta-analysis of interventional studies. Diabetes Metab 2008;34:497-506.

37 Kaur PK, Narula SC, Rajput R, et al. Periodontal and glycemic effects of nonsurgical periodontal therapy in patients with type 2 diabetes stratified by baseline HbA1c. J Oral Sci 2015;57:201-11.

38 Taylor GW, Burt BA, Becker MP, et al. Severe periodontitis and risk for poor glycemic control in patients with non-insulin-dependent diabetes mellitus. J Periodontol 1996;67:1085-93.

39 Teeuw WJ, Gerdes VEA, Loos BG. Effect of periodontal treatment on glycemic control of diabetic patients: a systematic review and metaanalysis. Diabetes Care 2010;33:421-7.

40 Al-Rafee MA. The epidemiology of edentulism and the associated factors: a literature review. J Family Med Prim Care 2020;9:1841-3.

41 Ishikawa S, Konta T, Susa S, et al. Risk factors for tooth loss in community-dwelling Japanese aged 40 years and older: the Yamagata (Takahata) study. Clin Oral Investig 2019;23:1753-60.

42 Walsh T, Worthington HV, Glenny A-M, et al. Fluoride toothpastes of different concentrations for preventing dental caries. Cochrane Database Syst Rev 2019;3:CD007868.

43 Arora M, Schwarz E, Sivaneswaran S, et al. Cigarette smoking and tooth loss in a cohort of older Australians: the 45 and up study. J Am Dent Assoc 2010;141:1242-9.

44 Watt RG, Daly B, Allison P, et al. Ending the neglect of global oral health: time for radical action. Lancet 2019;394:261-72.

45 Tonetti MS, Jepsen S, Jin L, et al. Impact of the global burden of periodontal diseases on health, nutrition and wellbeing of mankind: a call for global action. J Clin Periodontol 2017;44:456-62.

$46 \mathrm{Fu} \mathrm{W,} \mathrm{Lv} \mathrm{C,} \mathrm{Zou} \mathrm{L,} \mathrm{et} \mathrm{al.} \mathrm{Meta-Analysis} \mathrm{on} \mathrm{the} \mathrm{association} \mathrm{between}$ the frequency of tooth brushing and diabetes mellitus risk. Diabetes Metab Res Rev 2019;35:e3141.

47 Raskiliene A, Kriaucioniene V, Siudikiene J, et al. Self-Reported oral health, oral hygiene and associated factors in Lithuanian adult population, 1994-2014. Int J Environ Res Public Health 2020;17:5331.

48 de Pereira M, Oliveira L, Lunet N. Caries and oral health related behaviours among homeless adults from Porto, Portugal. Oral Health Prev Dent 2014;12:109-16. 